\title{
Treatment Policy and Liver Histopathology Predict Biliary Atresia Outcomes : Results after National Centralization and Protocol Biopsies
}

\author{
Hukkinen, Maria
}

2018-01

Hukkinen, M , Kerola , A , Lohi , J , Heikkilä , P , Merras-Salmio , L , Jahnukainen , T , Koivusalo , A , Jalanko , H \& Pakarinen, M P 2018 , ' Treatment Policy and Liver

Histopathology Predict Biliary Atresia Outcomes : Results after National Centralization and Protocol Biopsies ' , Journal of the American College of Surgeons , vol. 226 , no. 1 , pp. 46-57 . https://doi.org/10.1016/j.jamcollsurg.2017.09.009

http://hdl.handle.net/10138/300142

https://doi.org/10.1016/j.jamcollsurg.2017.09.009

publishedVersion

Downloaded from Helda, University of Helsinki institutional repository.

This is an electronic reprint of the original article.

This reprint may differ from the original in pagination and typographic detail.

Please cite the original version. 


\title{
Treatment Policy and Liver Histopathology Predict Biliary Atresia Outcomes: Results after National Centralization and Protocol Biopsies
}

\author{
Maria Hukkinen, MD, PhD, Anna Kerola, MD, Jouko Lohi, MD, PhD, Päivi Heikkilä, MD, PhD, \\ Laura Merras-Salmio, MD, PhD, Timo Jahnukainen, MD, PhD, Antti Koivusalo, MD, PhD, \\ Hannu Jalanko, MD, PhD, Mikko P Pakarinen, MD, PhD
}

\begin{abstract}
BACKGROUND: Different treatment policies can influence biliary atresia outcomes, but the pathophysiology of expanding fibrosis occurring even after successful portoenterostomy remains unclear.

STUDY DESIGN: Clearance of jaundice (COJ) (bilirubin $<20 \mu \mathrm{mol} / \mathrm{L}$ ), native liver survival, and overall survival rates of biliary atresia patients were analyzed before and after national centralization of management, as well as in relation to native liver histopathology of protocol biopsies.

RESULTS: Of the 59 patients, 35 were managed after centralization and received standardized postoperative adjuvant therapy, including corticosteroids. After centralization, age at portoenterostomy decreased from 73 days to 54 days $(\mathrm{p}=0.014)$ and COJ rate increased from $42 \%$ to $80 \%$ $(p=0.005)$, 5-year native liver survival increased from $38 \%$ to $70 \%(p=0.014)$, and 5 -year overall survival increased from $68 \%$ to $94 \%(\mathrm{p}=0.007)$. High-grade portal inflammation at portoenterostomy predicted COJ (odds ratio 3.66; $\mathrm{p}=0.011$ ) and slower fibrosis progression $(\beta=-0.74 ; p=0.005)$. Native liver survival was extended in patients with high-grade portal inflammation $(\mathrm{p}=0.002)$ and in patients whose bilirubin normalized within 3 months $(\mathrm{p}<$ $0.001)$. Portal inflammation and cholestasis reduced only after COJ $(\mathrm{p}<0.001)$, and persisting ductal reaction, reflected by cytokeratin 7-positive proliferating bile ductules and periportal hepatocytes, correlated with follow-up fibrosis $(r=0.454$ to $0.763 ; \mathrm{p}<0.001$ to 0.003$)$. Cytokeratin 7 immunopositivity of periportal hepatocytes increased after COJ $(\mathrm{p}=0.015)$ and was the only predictor of follow-up liver fibrosis $(\beta=0.36 ; \mathrm{p}=0.002)$ in multiple regression.

CONCLUSIONS: Biliary atresia outcomes improved significantly after centralization and standardized management. Resolution of cholestasis and reduction of high-grade portal inflammation postoperatively predict slower fibrosis progression and improved native liver survival, and persisting ductal reaction parallels progressive native liver fibrosis despite COJ. (J Am Coll Surg 2018;226:46-57. (C) 2017 by the American College of Surgeons. Published by Elsevier Inc. All rights reserved.)
\end{abstract}

Disclosure Information: Nothing to disclose.

Support: This study was supported by the Sigrid Jusélius Foundation, the Finnish Pediatric Research Foundation, and the Helsinki University Central Hospital Grant \#TYH2015219.

Drs Hukkinen and Kerola contributed equally to this work.

Received June 19, 2017; Revised July 28, 2017; Accepted September 7, 2017.

From the Pediatric Liver and Gut Research Group (Hukkinen, Kerola, Merras-Salmio, Koivusalo, Pakarinen), Section of Pediatric Surgery (Hukkinen, Kerola, Koivusalo, Pakarinen), Departments of Pediatric Gastroenterology (Merras-Salmio), Pediatric Nephrology and Transplantation (Jahnukainen, Jalanko), Children's Hospital, and Department of Pathology, HUSLAB (Lohi, Heikkilä), Helsinki University Hospital, Helsinki, Finland.

Correspondence address: Mikko P Pakarinen, MD, PhD, Section of Pediatric Surgery, Children's Hospital, Helsinki University Hospital, PO Box 281, 00029 HUS, Helsinki, Finland. email: mikko.pakarinen@hus.fi
Biliary atresia (BA) is an idiopathic cholangiopathy of infancy characterized by fibro-inflammatory obstruction of extrahepatic bile ducts, leading to cholestasis and eventually cirrhosis. ${ }^{1}$ Adjacent to biliary fibrosis, chronic cholestasis promotes proliferation of bile ductules, called ductal reaction. ${ }^{2}$ The first-line treatment for BA is portoenterostomy (PE), which typically restores adequate bile flow in approximately half of patients. ${ }^{3-7}$ It remains unclear why destruction of intrahepatic bile ducts, which promotes progressive liver damage, continues after resolution of jaundice. ${ }^{8}$ Additional understanding of the pathophysiology driving liver injury is essential for novel approaches designed to extend native liver survival. Biliary atresia is the most common indication for pediatric liver 


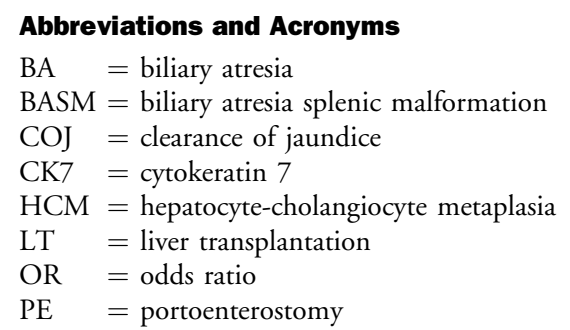

transplantation (LT), which is required in $70 \%$ to $80 \%$ of patients within 20 years of PE. ${ }^{9,10}$

After successful PE, plasma bilirubin levels normalize, which postpones the need for LT and improves patient survival. ${ }^{11,12}$ Portoenterostomy success rates are influenced by several patient-dependent factors, such as age at operation, ${ }^{3,6,13}$ anatomy of the biliary tract remnant, ${ }^{13,14}$ coexistent congenital malformations, ${ }^{3,6,7}$ and liver histologic features at PE, including degrees of fibrosis and ductal reaction. ${ }^{15-18}$ Postoperative steroids can improve clearance of jaundice (COJ) rates, although their effect on native liver survival remains unestablished. ${ }^{19,20}$ In addition, hospitals with low caseloads can have inferior outcomes compared with more experienced centers, ${ }^{4,721}$ which has led to centralization of BA treatment, at least in the UK and Finland. ${ }^{4,21}$

After national centralization of BA management in Finland to Helsinki University Children's Hospital, results of the initial short-term follow-up demonstrated significantly improved COJ and transplant-free survival rates. ${ }^{4}$ To improve $\mathrm{BA}$ management and to better understand the pathophysiology behind progressive liver damage, protocol native liver biopsies at $\mathrm{PE}$ and during follow-up were started after centralization. ${ }^{22}$ Here, we evaluate the effect of centralization on BA outcomes after more than a decade of follow-up and compare the outcomes with those obtained in Helsinki before centralization. In addition, we address predictors of COJ, native liver survival, and overall survival, and analyze how liver histopathology at PE and during follow-up relates to these outcomes.

\section{METHODS \\ Ethics}

This study was approved by the Ethical Committee of Helsinki University Hospital and the Finnish National Authority of Medicolegal Affairs and Health. A consent from participants or their caregivers was obtained before any procedures.

\section{Patients}

In 2005, the Ministry of Health centralized BA management in Finland from 5 university hospitals to Helsinki University Children's Hospital, which is a tertiary referral center for pediatric liver diseases with a nationwide LT program since 1987. All BA patients managed in Helsinki during 1987 to 2016 with at least a 4-month follow-up after primary operation were included. Biliary atresia diagnosis was confirmed by operative findings; perioperative cholangiography, when possible; and histopathologic assessment of the biliary remnant. Medical records were reviewed for gestational age and weight, associated congenital malformations, anatomic type of $\mathrm{BA},{ }^{23}$ details of operative management, COJ rate, LT listing and performance, and possible death. Biliary atresia splenic malformation syndrome (BASM) was defined as presence of poly- or asplenia. ${ }^{24}$ Clearance of jaundice was defined as serum total bilirubin $<20 \mu \mathrm{mol} / \mathrm{L}$ at any time point postoperatively. Bilirubin levels were recorded at 3 and 6 months after PE, as well as at last follow-up.

\section{Management of biliary atresia}

In contrast to the variable follow-up and medical management practices performed before centralization, management and follow-up of BA were standardized in 2005, and a single team led by 1 surgeon operated on patients thereafter. Ursodeoxycholic acid $(30 \mathrm{mg} / \mathrm{kg} / \mathrm{d})$, thrimetoprim-sulfadiazine $(4+12.5 \mathrm{mg} / \mathrm{kg} / \mathrm{d})$, and dexamethasone with decreasing doses $(0.6$ to $0.2 \mathrm{mg} / \mathrm{kg} / \mathrm{d}$, days 5 to 28) were routinely administered postoperatively. ${ }^{25-27}$ Enteral energy provision was aimed at $150 \mathrm{kcal} / \mathrm{kg} / \mathrm{d}$ with use of carbohydrate and medium chain fatty acid energy supplements. ${ }^{28}$ Fat-soluble vitamin supplements were continued after discharge together with ursodeoxycholic acid and thrimetoprim-sulfadiazine., ${ }^{4,28}$ Follow-ups were arranged at 3-month intervals in local hospitals and at least once a year in Helsinki.

\section{Liver histology}

Liver biopsies at PE and at last follow-up were analyzed and the changes occurring in histology over time were evaluated according to COJ status. Routine follow-up biopsies were initiated in 2005 and performed 1, 5, and 10 years after PE or when clinically indicated. Follow-up biopsies were taken percutaneously with ultrasound guidance under general anesthesia for endoscopic variceal surveillance. ${ }^{29}$ For patients who underwent LT, followup liver histology was mainly based on the explant.

In addition to conventional stains, immunostaining for cytokeratin 7 (CK7) was performed using a rabbit antihuman monoclonal antibody and ultra View Universal DAB Detection Kit (Ventana). Two experienced pediatric 
pathologists blinded to clinical data re-reviewed the slides until consensus was reached. Specimens were analyzed for portal inflammation (the extent of portal cellular infiltrate, scored 0 to 3), intracellular, intracanalicular, and ductal cholestasis (scored 0 to 3), and fibrosis (Metavir stage 0 to 4). ${ }^{30}$ Ductal reaction was visualized by CK7 staining in proliferative bile ductules (scored 0 to 2 ) and adjacent hepatocyte-cholangiocyte metaplasia (HCM) by CK7 staining in periportal hepatocytes (scored 0 to 4). ${ }^{15,17,22}$ The changes of Metavir, CK7 immunostaining, and portal inflammation scores between PE and followup were calculated. Fibrosis progression rate (not calculated for patients with Metavir = stage 4 at PE, $\mathrm{n}=7$ ) was defined as the change of Metavir score divided by the years between PE and follow-up biopsies, and expressed as change in Metavir score/year.

\section{Statistical methods}

Continuous data are expressed as median values with interquartile ranges (IQR) and categorical data as frequencies unless otherwise stated. Kruskal-Wallis and Mann-Whitney $U$ tests were used to compare independent continuous variables, Wilcoxon signed-rank test to compare repeated measurements, and Fisher's exact test to compare frequencies between groups. Associations between variables were examined with Spearman rank correlation.

Predictors of COJ, bilirubin levels at 3 months after $\mathrm{PE}$, follow-up Metavir score, and fibrosis progression rate were evaluated with regression analyses. For COJ, odds ratios (OR) with 95\% CIs were generated by binary logistic regression, and linear regression was used for continuous variables. Predictors showing significant associations with outcomes variables in simple regression were included in multiple regression analyses.

Cumulative native liver and overall survival rates were analyzed with Kaplan-Meier curves. Univariate predictors of survival were evaluated with the log-rank test. Multivariate survival models were performed by generating hazard ratios with 95\% CIs with Cox proportional hazards regression model, adjusted for statistically significant variables from univariate models and for age at $\mathrm{PE}^{3,6,7}$ for native liver survival. The level of significance was set at $\mathrm{p}<0.05$ and all analyses were performed with SPSS, version 24 (IBM Corp).

\section{RESULTS}

\section{Baseline characteristics}

Altogether 63 patients were identified. Two patients were excluded; 1 died of heart defect before operation and the other with multiple severe anomalies died few weeks after
PE; no COJ status for him could be defined. The remaining 61 patients were divided into cohorts $\mathrm{A}(\mathrm{n}=25 \mathrm{pa}-$ tients [41\%]) and $\mathrm{B}(\mathrm{n}=36$ [59\%]), depending on whether they were treated before (cohort A) or after (cohort B) the decree on national centralization came into force in 2005. Altogether, 59 patients underwent $\mathrm{PE}$ and 1 patient from both cohorts underwent primary LT due to delayed diagnosis and liver failure.

Based on annual birth rates in Finland, ${ }^{31}$ the incidence of BA was 1:18,600. Median annual caseload was 1 (IQR 1 to 2) before and 3.5 (IQR 2 to 4.3) after centralization. Cohort B patients underwent PE at younger age, had lower birth weight, and tended to be born earlier and have lower preoperative bilirubin compared with cohort A (Table 1). Median age at PE was 64 (IQR 39 to 85) days.

Liver biopsies at time of PE were available for half (12 of 24) of cohort A and 97\% (34 of 35) of cohort B patients. At PE, histologic features consisted of moderate to severe fibrosis, portal inflammation, ductal reaction, and cholestasis (Table 1). Ductal reaction and associated periportal HCM correlated with age at operation $(\mathrm{r}=$ $0.679 ; \mathrm{p}<0.001$ and $\mathrm{r}=0.463 ; \mathrm{p}=0.002$, respectively) and degree of fibrosis $(\mathrm{r}=0.539 ; \mathrm{p}<0.001$ and $\mathrm{r}=$ $0.454 ; \mathrm{p}=0.002$, respectively). Portal inflammation showed no association with baseline characteristics.

\section{Clearance of jaundice}

The proportion of patients clearing their jaundice almost doubled after centralization; 28 of $35(80 \%)$ vs 10 of 24 (42\%) ( $\mathrm{p}=0.005)$. In total $26 \%$ (10 of 38$)$ achieved $\mathrm{COJ}$ later than 3 months after operation, and COJ rate at 3 months was $65 \%$ in cohort $\mathrm{B}$ vs $32 \%$ in cohort $\mathrm{A}$ $(p=0.028)$. Median time to COJ showed no difference between cohorts $\mathrm{A}$ and $\mathrm{B}$ (3.2 [IQR 1.8 to 6.3] months vs 2.3 [IQR 0.84 to 3.6] months; $\mathrm{p}=0.272$ ). At 3 and 6 months after operation, cohort $\mathrm{B}$ patients had lower bilirubin than cohort A patients (11 [IQR 6.0 to 27] $\mu \mathrm{mol} / \mathrm{L}$ vs 135 [IQR 12 to 283 ] $\mu \mathrm{mol} / \mathrm{L} ; \mathrm{p}<0.001$ and 7.5 [IQR 3.5 to 27 ] $\mu \mathrm{mol} / \mathrm{L}$ vs 182 [IQR 8.0 to 239 ] $\mu \mathrm{mol} / \mathrm{L}$; $\mathrm{p}=0.008$ ).

In logistic regression, operation after centralization (OR 5.60; 95\% CI 1.76 to $17.9 ; \mathrm{p}=0.004$ ), highgrade portal inflammation (OR 3.66; 95\% CI 1.35 to 9.97; $\mathrm{p}=0.011$ ), and young age at operation (OR 0.98 ; $95 \%$ CI 0.97 to $1.00 ; \mathrm{p}=0.025)$ predicted COJ. In multiple regression, only the effect of portal inflammation remained significant (OR 3.82; 95\% CI 1.23 to 11.9; $\mathrm{p}=0.020)$.

Variables associated with bilirubin levels at 3 months in linear regression were operation before centralization $(\beta=165 ; 95 \%$ CI 77.6 to $252 ; p<0.001)$, age at PE 
Table 1. Baseline Characteristics and Liver Biopsy Findings at Portoenterostomy

\begin{tabular}{|c|c|c|c|c|}
\hline Characteristic & $\begin{array}{c}\text { Cohort A 1987-2004 } \\
(n=25)\end{array}$ & $\begin{array}{c}\text { Cohort B 2005-2016 } \\
(n=36)\end{array}$ & $\begin{array}{c}\text { p Value } \\
\text { (cohort A vs B) } \\
\end{array}$ & $\begin{array}{l}\text { Both cohorts } \\
(n=61)\end{array}$ \\
\hline Gestational age, wk, median (IQR) & $40(39-41)$ & $39(38-40)$ & 0.055 & $39(38-40)$ \\
\hline Gestational weight, g, median (IQR) & $3,260(3,265-3,865)$ & $3,264(2,928-3,600)$ & 0.014 & $3,390(3,083-3,703)$ \\
\hline Female, n (\%) & $14(56)$ & $19(53)$ & 1.000 & $33(54)$ \\
\hline \multicolumn{5}{|l|}{ Type of biliary atresia, $\mathrm{n}(\%)$} \\
\hline 1 & $1(4.0)$ & $1(2.8)$ & 1.000 & $2(3.3)$ \\
\hline 2 & $2(8.0)$ & $2(5.6)$ & & $4(6.6)$ \\
\hline 3 & $22(88)$ & $33(92)$ & & $55(90)$ \\
\hline Age at PE, d, median (IQR) & $73(53-101)$ & $54(28-79)$ & 0.016 & $64(40-85)$ \\
\hline Associated malformations, n (\%) & $9(36)$ & $13(36)$ & 1.000 & $22(36)$ \\
\hline Biliary atresia splenic malformation, $\mathrm{n}(\%)$ & $5(20)$ & $5(14)$ & 0.727 & $10(16)$ \\
\hline Preoperative bilirubin, $\mu \mathrm{mol} / \mathrm{L}$, median (IQR) & $186(146-214)$ & $145(111-191)$ & 0.067 & $169(132-207)$ \\
\hline \multicolumn{5}{|l|}{ Liver histology at PE, mean (range) } \\
\hline Fibrosis, Metavir, $0-4$ & $2.75(3)$ & $2.43(3)$ & 0.345 & $2.51(3)$ \\
\hline Portal inflammation, $0-3$ & $1.58(3)$ & $2.11(2)$ & 0.062 & $1.98(3)$ \\
\hline \multicolumn{5}{|l|}{ Cholestasis, mean (range) } \\
\hline Intracellular, $0-3$ & $1.67(2)$ & $2.17(2)$ & 0.078 & $2.04(2)$ \\
\hline Intracanalicular, $0-3$ & $2.00(2)$ & $2.40(2)$ & 0.095 & $2.30(2)$ \\
\hline Ductal, $0-3$ & $1.67(3)$ & $1.32(3)$ & 0.394 & $1.41(3)$ \\
\hline \multicolumn{5}{|l|}{ Cytokeratin 7 immunostaining, mean (range) } \\
\hline Periportal hepatocytes, $0-4$ & $1.17(1)$ & $1.27(3)$ & 0.621 & $1.24(3)$ \\
\hline Proliferating bile ductules, $0-2$ & $1.50(2)$ & $1.39(2)$ & 0.830 & $1.42(2)$ \\
\hline
\end{tabular}

Results are presented separately for patients treated before (cohort A) and after (cohort B) centralization of biliary atresia management in 2005. Bilirubin and age at operation data given for patients who underwent PE and not primary liver transplantation $(n=59)$.

CK7, cytokeratin 7; IQR, interquartile range; PE, portoenterostomy.

$(\beta=1.92 ; 95 \%$ CI 0.61 to $3.23 ; \mathrm{p}=0.005)$, and portal inflammation grade at PE $(\beta=-53.0 ; 95 \%$ CI 101 to $-5.41 ; p=0.030)$. Only the effect of centralization remained statistically significant in multiple regression $(\beta=95.0 ; 95 \%$ CI 8.91 to $181 ; p=0.031)$. Other clinical and histologic findings were unrelated with $\mathrm{COJ}$ and bilirubin levels at 3 months (eTable 1).

\section{Native liver survival}

Cumulative native liver survival for cohorts $\mathrm{A}$ and $\mathrm{B}$ were $37.5 \%( \pm$ SE $9.6 \%)$ and $77.6 \%( \pm 7.5)$ at 2 years; $37.5 \%$ $( \pm 9.9)$ and $70.2 \%( \pm 8.4)$ at 5 years; and $33.3 \%( \pm 9.6)$ and $65.2 \%( \pm 9.2)$ at 10 years, respectively (Fig. 1). Clearance of jaundice, bilirubin levels at 3 and 6 months postoperatively, portal inflammation grade at $\mathrm{PE}$, and centralization were significant predictors of native liver survival (Fig. 1, Table 2). Among cohort B patients, BASM and higher periportal HCM at PE predicted shorter native liver survival, and higher ductal reaction at $\mathrm{PE}$ tended to predict shorter native liver survival (Table 2).

Bilirubin at 3 months after operation was a better predictor compared with bilirubin at 6 months and was therefore chosen for the multivariate analysis. The hazard of death or transplantation was higher if bilirubin was $\geq 20 \mu \mathrm{mol} / \mathrm{L}$ at 3 months after operation (hazard ratio $11.0 ; 95 \%$ CI 2.38 to $50.4 ; \mathrm{p}=0.002$ ), and the effects of centralization, age, or portal inflammation remained insignificant.

\section{Liver transplantation}

During follow-up, 22 patients (11 from both cohorts, $44 \%$ and $31 \%$, respectively) underwent LT at age 1.15 (IQR 0.77 to 2.46 ) years. One patient from both cohorts underwent primary LT and 20 patients underwent LT after PE. Of them, the majority $(n=15)$ received transplants because of liver failure after an unsuccessful PE, and indications for LT after initial COJ were liver failure $(\mathrm{n}=1)$, recurrent variceal bleeding $(\mathrm{n}=1)$, recurrent cholangitis $(\mathrm{n}=1)$, hepatopulmonary syndrome $(\mathrm{n}=1)$, or refractory ascites $(\mathrm{n}=1)$. Two patients with BASM died after LT (2 of 5) compared with 17 transplanted patients without BASM surviving until the end of the follow-up (log-rank test; $p=0.006$ ). Centralization, COJ, or baseline characteristics were unrelated with post-LT survival, which was $91 \%$ at 2,5 , and 10 years (Fig. 2). One patient required a retransplantation. 

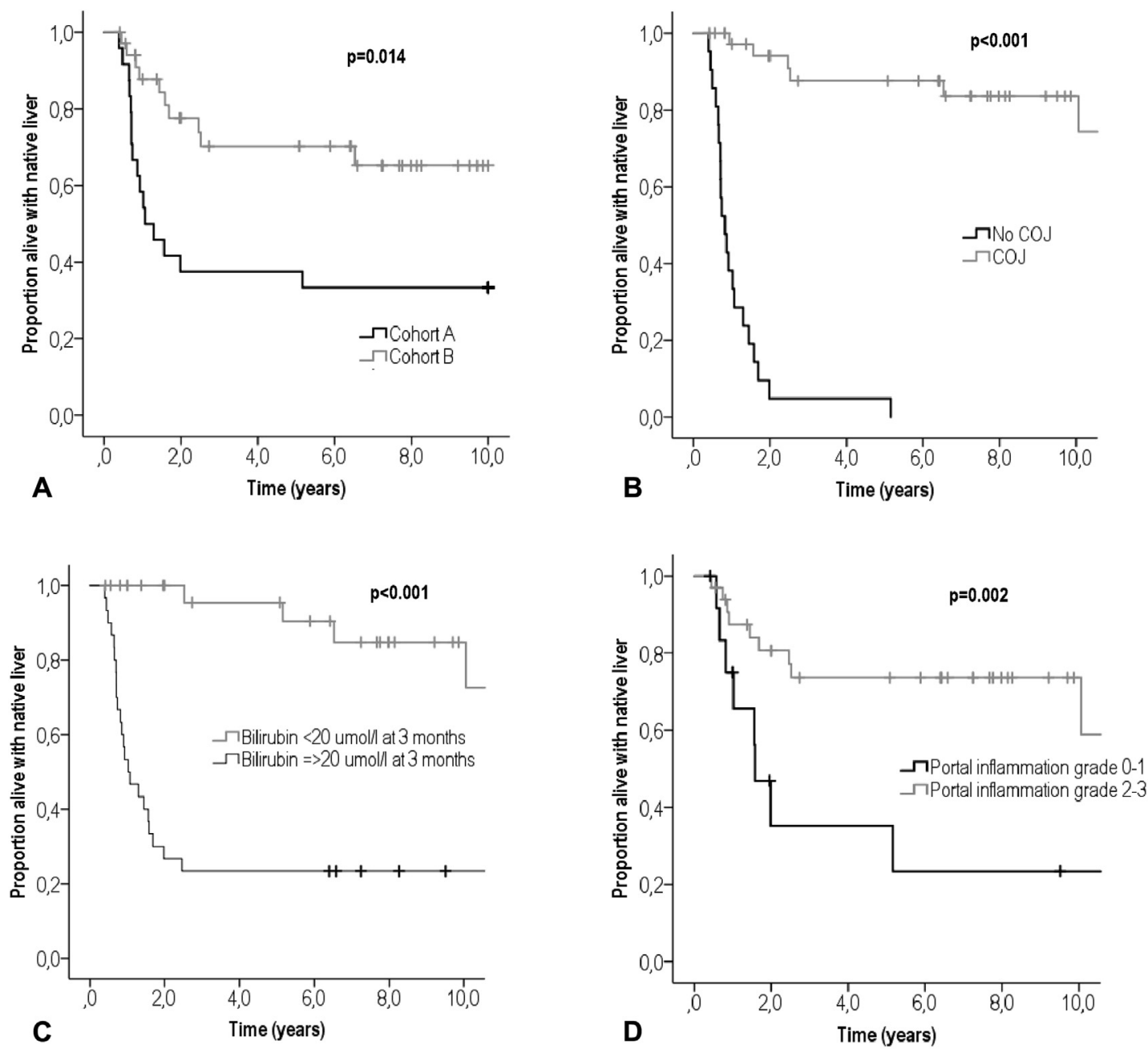

Figure 1. Cumulative native liver survival rates. Cumulative native liver survival according to (A) era of treatment, (B) clearance of jaundice (COJ) status, (C) plasma bilirubin levels at 3 months after portoenterostomy (PE), and (D) portal inflammation grade at PE. Subgroups are compared with the log-rank test. Cohort A = 1987 to 2004; cohort B = 2005 to 2016.

\section{Overall survival}

During follow-up, 10 (16\%) patients died, more frequently in cohort A than B (8 of 25 vs 2 of 36; $\mathrm{p}=0.011)$. All deaths occurred at age younger than 2 years, so the cumulative 2-year survival was equal to 5 - and 10-year survival rates, that is $68.0 \%( \pm 9.3)$ in cohort A and $93.7 \%( \pm 4.3)$ in cohort B ( $\mathrm{p}=0.007$, Table 3). Reasons for death were complications of advanced liver disease $(n=7)$, intestinal perforation $(n=1)$, volvulus $(n=1)$, and heart failure $(n=1)$. Three patients died on LT waiting list and only 1 of the deceased patients had cleared his jaundice after PE.

Univariate analyses suggested survival was better among patients whose bilirubin decreased $<20 \mu \mathrm{mol} / \mathrm{L}$ within 3 months of operation $(p=0.001)$ and who were operated on after centralization ( $p=0.007$ ) (Table 3). Neither predictor remained significant in multivariate analysis.

\section{Follow-up liver histology}

Follow-up biopsies were available for 29\% (7 of 24) of cohort $\mathrm{A}$ and $86 \%$ (30 of 35 ) of cohort $\mathrm{B}$ patients, and were missing for those aged younger than 1.5 years. Patients who cleared their jaundice underwent follow-up biopsies at older median age than others (4.73 [IQR 3.13 to 6.25 ] years vs 0.91 [IQR 0.70 to 1.51 ] years; $\mathrm{p}<0.001$ ).

Fibrosis and periportal HCM increased and ductal reaction persisted in all patients after PE, and cholestasis and portal inflammation decreased only after successful $\mathrm{PE}$ and remained unchanged if no COJ was achieved (Fig. 3, Table 4). Follow-up fibrosis scores correlated 
Table 2. Univariate Analysis of 5-Year Kaplan-Meier Native Liver Survival with Cumulative 5-Year Survival Estimates

\begin{tabular}{|c|c|c|c|c|c|c|}
\hline \multirow[b]{2}{*}{ Univariate } & \multicolumn{3}{|c|}{ Cohort B 2005-2016 $(n=35)$} & \multicolumn{3}{|c|}{ Both cohorts 1987-2016 $(n=59)$} \\
\hline & Patients, n & $\begin{array}{c}\text { 5-year NL survival, } \\
\%, \text { mean (SE) }\end{array}$ & p Value & Patients, n & $\begin{array}{c}\text { 5-year NL survival, } \\
\%, \text { mean (SE) }\end{array}$ & p Value \\
\hline Age at portoenterostomy & & & 0.674 & & & 0.392 \\
\hline $64 \mathrm{~d}$ or younger & 22 & $72.6(10.6)$ & & 32 & $62.1(9.1)$ & \\
\hline Older than $64 \mathrm{~d}$ & 13 & $64.6(14.3)$ & & 27 & $44.2(10.0)$ & \\
\hline Biliary atresia splenic malformation & & & 0.023 & & & 0.705 \\
\hline No & 30 & $77.0(8.3)$ & & 49 & $58.0(7.4)$ & \\
\hline Yes & 5 & $40.0(21.9)$ & & 10 & $50.0(15.8)$ & \\
\hline Associated malformations & & & 0.311 & & & 0.995 \\
\hline No & 22 & $74.3(9.9)$ & & 38 & $54.9(8.4)$ & \\
\hline Yes & 13 & $62.9(15.0)$ & & 21 & $59.3(11.3)$ & \\
\hline Type of biliary atresia & & & 0.278 & & & 0.448 \\
\hline 1 or 2 & 3 & 100.0 & & 6 & $83.3(15.2)$ & \\
\hline 3 & 32 & $66.9(9.2)$ & & 53 & $52.9(7.2)$ & \\
\hline Bilirubin at $3 \mathrm{mo}$ & & & 0.001 & & & $<0.001$ \\
\hline$<20 \mu \mathrm{mol} / \mathrm{L}$ & 22 & $93.3(6.4)$ & & 29 & $95.5(4.4)$ & \\
\hline$\geq 20 \mu \mathrm{mol} / \mathrm{L}$ & 13 & $38.5(13.5)$ & & 30 & $23.3(7.7)$ & \\
\hline Bilirubin at $6 \mathrm{mo}^{*}$ & & & 0.013 & & & $<0.001$ \\
\hline$<20 \mu \mathrm{mol} / \mathrm{L}$ & 20 & $92.3(7.4)$ & & 28 & $91.2(6.0)$ & \\
\hline$\geq 20 \mu \mathrm{mol} / \mathrm{L}$ & 13 & $46.2(13.8)$ & & 24 & $33.3(9.6)$ & \\
\hline Fibrosis, Metavir & & & 0.671 & & & 0.543 \\
\hline $0-2$ & 22 & $70.7(10.1)$ & & 28 & $58.6(9.6)$ & \\
\hline $3-4$ & 12 & $68.2(15.4)$ & & 18 & $73.9(11.3)$ & \\
\hline Portal inflammation & & & 0.056 & & & 0.002 \\
\hline $0-1$ & 7 & $44.4(22.2)$ & & 13 & $35.2(15.2)$ & \\
\hline $2-3$ & 27 & $75.1(8.9)$ & & 33 & $73.6(8.0)$ & \\
\hline Intracellular cholestasis & & & 0.327 & & & 0.887 \\
\hline $0-1$ & 10 & $80.0(12.6)$ & & 16 & $68.8(11.6)$ & \\
\hline $2-3$ & 24 & $64.2(11.1)$ & & 30 & $60.8(9.8)$ & \\
\hline CK7 expression in periportal hepatocytes ${ }^{\dagger}$ & & & 0.035 & & & 0.282 \\
\hline $0-1$ & 21 & $82.0(9.5)$ & & 31 & $70.9(8.7)$ & \\
\hline $2-4$ & 11 & $48.5(16.4)$ & & 13 & $49.0(14.8)$ & \\
\hline CK7-positive bile ductulus proliferation ${ }^{\dagger}$ & & & 0.070 & & & 0.172 \\
\hline $0-1$ & 16 & $84.6(10.0)$ & & 22 & $74.5(9.9)$ & \\
\hline 2 & 16 & $56.0(13.8)$ & & 22 & $54.6(11.4)$ & \\
\hline Centralization & & & - & & & 0.014 \\
\hline Before & 一 & 一 & & 24 & $37.5(9.9)$ & \\
\hline After & - & - & & 35 & $70.2(8.4)$ & \\
\hline
\end{tabular}

The $\mathrm{p}$ values from the log-rank test are reported. Results presented separately for cohort $\mathrm{B}$ and for the whole sample.

*Bilirubin data at 6 months missing for patients who received liver transplant $(\mathrm{n}=2)$ or died $(\mathrm{n}=4)$ before 6 months of PE or in whom bilirubin was not measured at 6 months $(\mathrm{n}=1)$.

${ }^{\dagger}$ Two biopsies were not analyzed for CK7 immunostaining scores.

CK7, cytokeratin 7; NL, native liver.

with follow-up ductal reaction $(\mathrm{r}=0.494 ; \mathrm{p}=0.003)$ and were closely related with periportal HCM, portal inflammation, and their increase during follow-up (Fig. 4). In simple regression, follow-up fibrosis score was associated with biopsy timing after $\mathrm{PE}(\beta=-0.09$; $95 \% \mathrm{CI}-0.18$ to $-0.003 ; \mathrm{p}=0.044)$, COJ $(\beta=1.03$;
$95 \% \mathrm{CI} 0.16$ to $1.91 ; \mathrm{p}=0.022)$, intracellular $(\beta=0.49$; $95 \%$ CI 0.09 to $0.89 ; \mathrm{p}=0.018)$, and intracanalicular $(\beta=0.41 ; 95 \%$ CI 0.07 to $0.74 ; \mathrm{p}=0.018$ ) cholestasis, ductal reaction $(\beta=0.86 ; 95 \%$ CI 0.41 to 1.31; $\mathrm{p}<0.001)$, as well as follow-up portal inflammation $(\beta=0.99 ; 95 \%$ CI 0.62 to $1.36 ; \mathrm{p}<0.001)$ and 


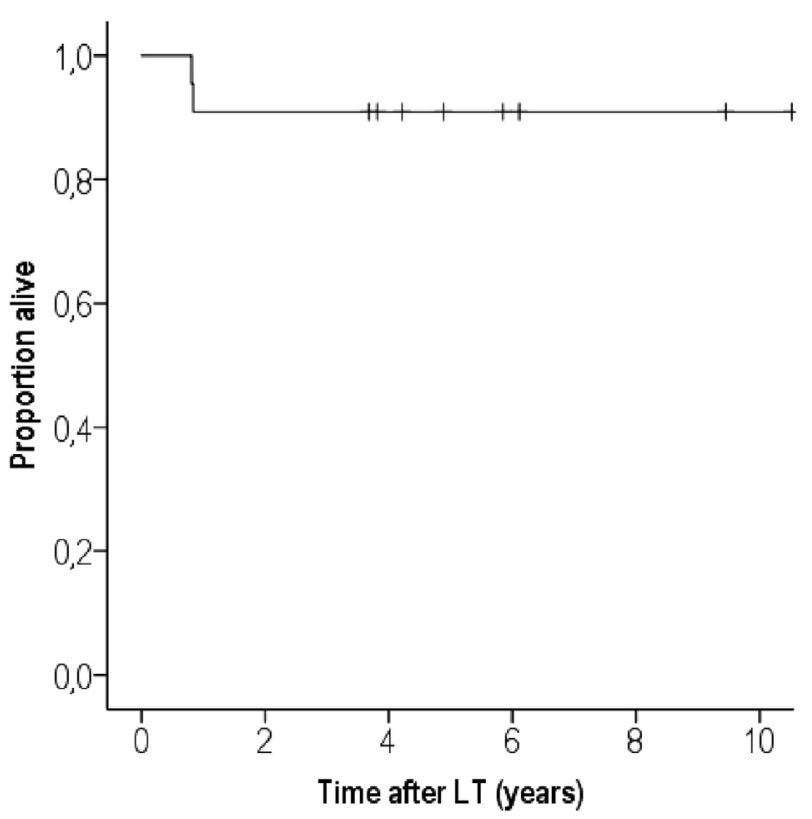

Figure 2. Cumulative survival after liver transplantation (LT). Cumulative survival after LT for all transplanted patients from cohorts $A$ and $B(n=22)$.

HCM scores ( $\beta=0.52 ; 95 \%$ CI 0.36 to $0.68 ; \mathrm{p}<0.001)$ and their observed change after PE ( $\beta=-0.61 ; 95 \% \mathrm{CI}$
-0.88 to $-0.34 ; \mathrm{p}<0.001$ and $\beta=0.41 ; 95 \% \mathrm{CI}$ 0.23 to $0.59 ; \mathrm{p}<0.001$ ). In multiple regression (where absolute scores were used instead of their change, and intracellular cholestasis was used to reflect the influence of cholestasis), only the effect of periportal HCM remained significant ( $\beta=0.36$; $95 \%$ CI 0.14 to $0.58 ; \mathrm{p}=0.002$ ). Age, histology at PE, time to COJ, or other clinical characteristics were unrelated with follow-up fibrosis.

\section{Progression of histologic fibrosis and its predictors}

Compared with patients who did not achieve COJ, those whose bilirubin normalized presented at follow-up with lower degrees of fibrosis $(p=0.029$, Table 4$)$, tendency toward smaller increase in fibrosis during follow-up (mean 1.83 [range 2.0] vs 0.79 [range 5.0]; $\mathrm{p}=0.057$ ), and slower fibrosis progression rate ( $\mathrm{p}<0.001$, Fig. 5).

In simple regression, variables associated with fibrosis progression rate were biopsy timing after $\mathrm{PE}(\beta=-0.12 ; 95 \%$ $\mathrm{CI}-0.20$ to $-0.04 ; \mathrm{p}=0.006)$, $\mathrm{COJ}(\beta=1.81 ; 95 \% \mathrm{CI}$ 1.18 to 2.44; $\mathrm{p}<0.001$ ), portal inflammation score at $\mathrm{PE}$ $(\beta=-0.74 ; 95 \% \mathrm{CI}-1.24$ to $-0.24 ; \mathrm{p}=0.005)$, and change of portal inflammation during follow-up ( $\beta=-0.73 ; 95 \% \mathrm{CI}-1.24$ to $-0.23 ; \mathrm{p}=0.006)$. In a multiple regression model, only the effect of COJ remained significant $(\beta=1.60$; $95 \%$ CI 0.84 to 2.35 ; $\mathrm{p}<0.001)$.

Table 3. Univariate Analysis of 5-Year Kaplan-Meier Overall Survival Estimates

\begin{tabular}{|c|c|c|c|c|c|c|}
\hline \multirow[b]{2}{*}{ Univariate } & \multicolumn{3}{|c|}{ Cohort B 2005-2016 $(n=36)$} & \multicolumn{3}{|c|}{ Both cohorts $1987-2016(n=61)$} \\
\hline & Patients, $\mathbf{n}$ & $\begin{array}{c}\text { 5-y survival, \%, } \\
\text { mean (SE) }\end{array}$ & p Value & Patients, n & $\begin{array}{c}\text { 5-y survival, \%, } \\
\text { mean (SE) }\end{array}$ & p Value \\
\hline Age at portoenterostomy & & & 0.683 & & & 0.700 \\
\hline $64 \mathrm{~d}$ or younger & 22 & $95.2(4.6)$ & & 32 & $84.7(7.0)$ & \\
\hline Older than $64 \mathrm{~d}$ & 13 & $90.9(8.7)$ & & 27 & $80.5(7.2)$ & \\
\hline$\underline{B i l i a r y}$ atresia splenic malformation & & & 0.148 & & & 0.212 \\
\hline No & 31 & $96.2(3.8)$ & & 51 & $85.5(5.1)$ & \\
\hline Yes & 5 & $80.0(17.9)$ & & 10 & $70.0(14.5)$ & \\
\hline Associated malformations & & & 0.653 & & & 0.275 \\
\hline No & 23 & $95.0(4.9)$ & & 39 & $86.4(5.7)$ & \\
\hline Yes & 13 & $91.7(8.0)$ & & 22 & $77.0(9.0)$ & \\
\hline$\underline{\text { Bilirubin at } 3 \mathrm{mo}}$ & & & 0.090 & & & 0.001 \\
\hline$<20 \mathrm{mmol} / \mathrm{L}$ & 22 & 100 & & 29 & 100 & \\
\hline$\geq 20 \mathrm{mmol} / \mathrm{L}$ & 13 & $84.6(10.0)$ & & 30 & $66.7(8.6)$ & \\
\hline Bilirubin at $6 \mathrm{mo}^{*}$ & & & 0.283 & & & 0.151 \\
\hline$<20 \mu \mathrm{mol} / \mathrm{L}$ & 20 & 100 & & 28 & $96.0(3.9)$ & \\
\hline$\geq 20 \mu \mathrm{mol} / \mathrm{L}$ & 13 & $92.3(7.4)$ & & 24 & $83.3(7.6)$ & \\
\hline Centralization & & & 一 & & & 0.007 \\
\hline Before & - & - & & 25 & $68.0(9.3)$ & \\
\hline After & - & - & & 36 & $93.7(4.3)$ & \\
\hline
\end{tabular}

Results are presented separately for cohort B and for the whole sample. p Values from the log-rank test are reported. Bilirubin levels analyzed only for patients undergoing PE and not primary transplantation $(n=59)$.

*Bilirubin data at 6 months missing for patients who received liver transplantation $(n=2)$ or died $(n=4)$ before 6 months of PE or in whom bilirubin was not measured at 6 months $(\mathrm{n}=1)$. 

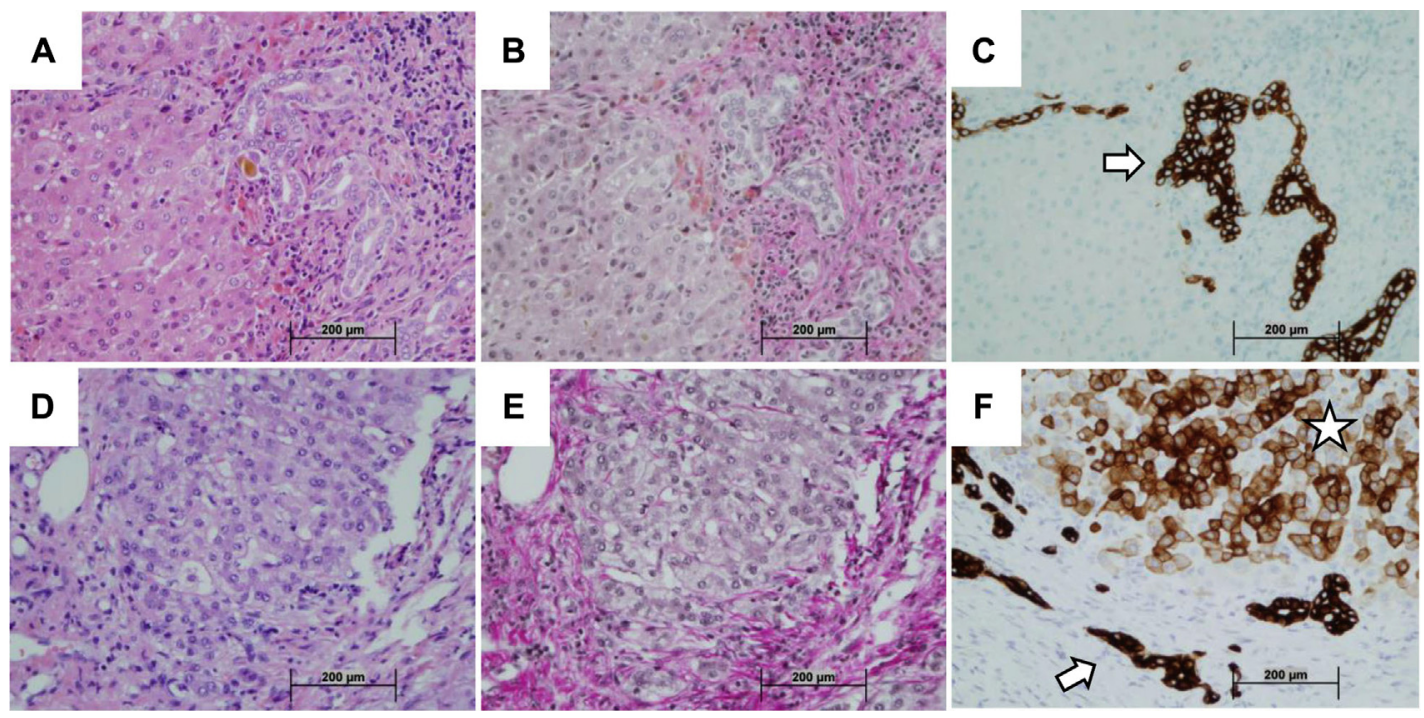

Figure 3. $(A-C)$ Representative native liver histology from the same patient at portoenterostomy (PE) and (D-F) 2.4 years after successful PE (200× magnification). Portal inflammation (0-3) reduced from grade 3 to 1 (A, D: hematoxylin and eosin). Metavir fibrosis stage ( $0-4)$ increased from 2 to 4 (B, E: Herovici stain). Ductal reaction (0-2, dark brown, arrow) increased from grade 1 to 2 and hepatocyte-cholangiocyte metaplasia in periportal hepatocytes (0-4, light brown, asterisk) from 0 to 4 (C, F: cytokeratin-7 staining).

\section{DISCUSSION}

This study demonstrates that national centralization of BA management and standardization of care can considerably improve outcomes, even exceeding those reported previously. ${ }^{3,732,33}$ Although the incidence of BA in Finland is equivalent to other European countries, ${ }^{6,21}$ the annual caseload inevitably remains lower, as Finland's population approximates 5.5 million. After centralization of management, COJ rate increased from $42 \%$ to $80 \%$, showing that excellent PE outcomes can be achieved, even with relatively low caseloads, if the treatment process is rationally planned. Reflecting COJ rates, both native liver and overall survival estimates improved significantly. In addition, this study provides novel evidence on BA liver histopathology and its relation to the clinical outcomes. High-grade portal inflammation at PE is associated with improved COJ rates and, consequently, with slower progression of fibrosis and longer native liver survival. Periportal HCM was the only predictor of followup fibrosis in multiple regression, and the extent of

Table 4. Liver Histologic Features at Time of Portoenterostomy and at Last Follow-Up

\begin{tabular}{|c|c|c|c|c|c|c|c|c|c|}
\hline \multirow[b]{2}{*}{ Histology } & \multicolumn{3}{|c|}{$\operatorname{coJ}(n=26)$} & \multicolumn{3}{|c|}{ No $\operatorname{coJ}(n=7)$} & \multicolumn{3}{|c|}{ All patients $(n=33)$} \\
\hline & $\begin{array}{c}\text { At PE, mean } \\
\text { (range) }\end{array}$ & $\begin{array}{l}\text { At follow-up, } \\
\text { mean } \\
\text { (range) }\end{array}$ & p Value & $\begin{array}{c}\text { At PE, } \\
\text { mean } \\
\text { (range) }\end{array}$ & $\begin{array}{l}\text { At follow-up, } \\
\text { mean } \\
\text { (range) }\end{array}$ & p Value & $\begin{array}{c}\text { At PE, } \\
\text { mean } \\
\text { (range) }\end{array}$ & $\begin{array}{l}\text { At follow-up, } \\
\text { mean } \\
\text { (range) }\end{array}$ & p Value \\
\hline Fibrosis, Metavir, 0-4 & $2.38(3)$ & $3.12^{*}(3)$ & 0.009 & $2.43(3)$ & $4.00(0)$ & 0.026 & $2.39(3)$ & $3.30(3)$ & 0.001 \\
\hline Portal inflammation, $0-3$ & $2.27^{\dagger}(2)$ & $1.00(2)$ & $<0.001$ & $1.71(2)$ & $1.43(2)$ & 0.414 & $2.15(2)$ & $1.09(3)$ & $<0.001$ \\
\hline \multicolumn{10}{|l|}{ Cholestasis } \\
\hline Intracellular, $0-3$ & $1.96(2)$ & $0.12^{\ddagger}(1)$ & $<0.001$ & $2.29(2)$ & $2.00(2)$ & 0.414 & $2.03(2)$ & $0.52(3)$ & $<0.001$ \\
\hline Intracanalicular, $0-3$ & $2.19(2)$ & $0.08^{\ddagger}(2)$ & $<0.001$ & $2.43(1)$ & $2.43(2)$ & 1.000 & $2.24(2)$ & $0.58(3)$ & $<0.001$ \\
\hline Ductal, $0-3$ & $1.15(3)$ & $0.00^{\dagger}(0)$ & $<0.001$ & $1.67(3)$ & $2.00(3)$ & 0.492 & $1.25(3)$ & $0.38(3)$ & 0.002 \\
\hline \multicolumn{10}{|l|}{ Cytokeratin 7 immunostaining } \\
\hline Periportal hepatocytes, $0-4$ & $1.17(4)$ & $2.04(2)$ & 0.015 & $1.50(2)$ & $2.67(2)$ & 0.066 & $1.23(2)$ & $2.17(4)$ & 0.003 \\
\hline Proliferating bile ductules, $0-2$ & $1.13(2)$ & $1.29(2)$ & 0.356 & $1.83(1)$ & $1.67(1)$ & 0.564 & $1.40(2)$ & $1.23(2)$ & 0.282 \\
\hline
\end{tabular}

Results are presented separately for patients who cleared or did not clear their jaundice after PE (bilirubin $<20$ vs $\geq 20 \mu \mathrm{mol} / \mathrm{L}$ ). Data are shown for 33 patients with liver histology available both at baseline and at follow-up. Wilcoxon signed-rank test $\mathrm{p}$ values for the difference between histology scores at operation and at follow-up are reported.

*Mann-Whitney U test $\mathrm{p}$ value $<0.05$ for the differences observed in histologic scores between COJ and no-COJ subgroups.

${ }^{\dagger}$ Mann-Whitney $\mathrm{U}$ test $\mathrm{p}$ value $<0.01$ for the differences observed in histologic scores between COJ and no-COJ subgroups.

${ }^{\ddagger}$ Mann-Whitney $U$ test $p$ value $<0.001$ for the differences observed in histologic scores between COJ and no-COJ subgroups.

COJ, clearance of jaundice; PE, portoenterostomy. 

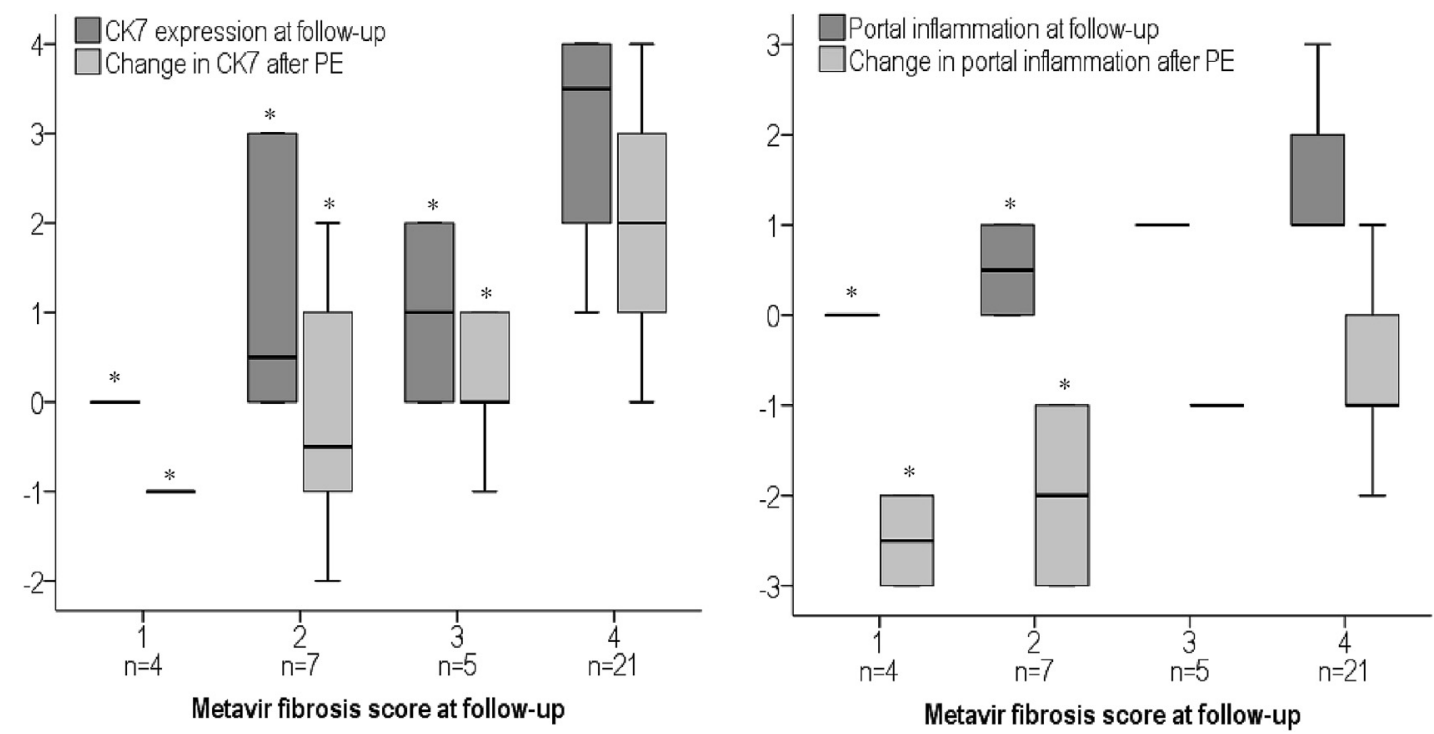

Figure 4. Cytokeratin (CK7) expression in periportal hepatocytes, portal inflammation score, and their observed change between portoenterostomy (PE) and follow-up biopsies according to follow-up Metavir fibrosis scores. The length of the box represents the interquartile range and the line through the middle of the box the median. Error bars show minimum and maximum values. Kruskal-Wallis test $p<0.001$ for CK7 expression; $p=0.003$ for change in CK7 expression; $\mathrm{p}<0.001$ for portal inflammation; and $\mathrm{p}=0.008$ for change in portal inflammation. *Statistically significant difference when compared with Metavir stage $=4(p<0.05)$.

both HCM and ductal reaction paralleled closely the degree of fibrosis at PE and its progression during follow-up. These findings suggest progression of liver damage is partly regulated by inflammation and ductal reaction.

After failed PE, BA patients die of liver failure within 2 years unless LT is performed. ${ }^{8}$ The PE success rates typically vary between $40 \%$ and $60 \%, 3,6,7,32$ with best outcomes reported so far from the UK, where BA treatment has been centralized in 3 hospitals, ${ }^{21}$ and from Japan, where BA incidence is remarkably higher compared with Europe. ${ }^{5}$ In this study, COJ and 5-year native liver survival rates almost doubled after centralization. Although age at operation decreased simultaneously, regression models suggested centralization was the most important factor predicting postoperative bilirubin levels. In French and Canadian national cohorts, hospitals with the lowest and highest caseloads achieved similar outcomes. ${ }^{6,33,34}$ Our post-centralization results also suggest that instead of absolute caseload numbers, BA outcomes are influenced by the quality of each treatment aspect, including early diagnosis and appropriate surgical technique, as well as standardized postoperative management and careful follow-up. ${ }^{25-27}$ Postoperative steroids can improve COJ in patients who undergo an early $\mathrm{PE},{ }^{19,25}$ suggesting children managed after centralization at median age of 54 days might have particularly benefited from adjuvant therapy. A combination of steroids, ursodeoxycholic acid, ${ }^{27}$ and antibiotics ${ }^{3,26}$ has been previously demonstrated to improve COJ and native liver survival. ${ }^{35,36}$ Unfortunately, because the use and dosage of postoperative medications was variable before centralization, their effect could not be controlled for in statistical analyses.

Bilirubin level at 3 months after operation reflects the success of $\mathrm{PE}$ and has outperformed the prognostic value of other factors on native liver survival in several large cohorts. $^{14,37-39}$ Also, in our patients, bilirubin at 3 months was the best predictor of native liver and overall survival, and centralization strongly influenced the postoperative reduction of bilirubin. Patients with BASM had higher post-LT mortality and shorter native liver survival in cohort $B$ than others. In addition to BASM, ${ }^{24,32,33}$ anatomic subtype of $\mathrm{BA}^{6,13,14}$ and age at $\mathrm{PE}^{3,6,7,13}$ can influence native liver survival. As splenic malformations and BA subtypes 1 to 2 each occur in about $10 \%$ of patients, ${ }^{24,38}$ their predictive value is evidently limited. Although increased age at operation relates with shorter transplant-free survival, whether it limits achievement of COJ remains unclear, ${ }^{3,7,14,38}$ and no threshold age beyond which PE would be futile has been set. ${ }^{10}$ Although we found bilirubin at 3 months as the best predictor of LT need, as much as $26 \%$ cleared their jaundice later. Frequent monitoring of clinical status and laboratory values are needed to distinguish between such patients and those who will require LT during infancy. 


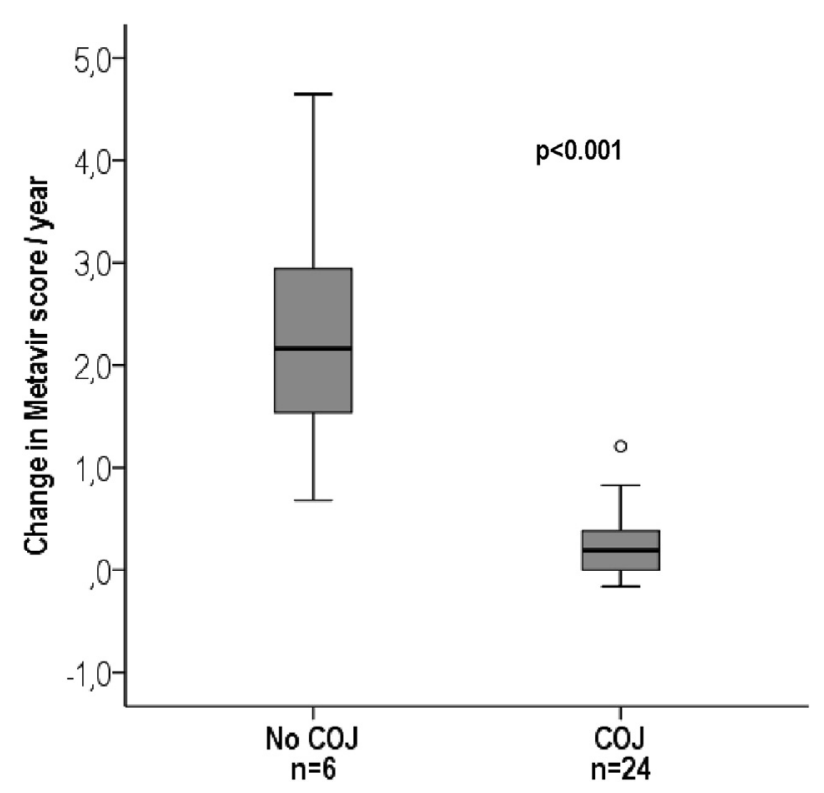

Figure 5. Fibrosis progression rate during follow-up in patients who cleared vs did not clear their jaundice after portoenterostomy (PE). Patients with Metavir stage 4 at PE $(n=7)$ are excluded from the analysis. The length of the box represents the interquartile range (IQR) and the line through the middle of each box the median. Error bars show minimum and maximum values. The round dot represents a value outside the upper quartile +1.5 times the IQR. MannWhitney $\mathrm{U}$ test $\mathrm{p}$ value is reported. COJ, clearance of jaundice.

Although previous abdominal operation can increase the risk of complications after LT, mortality after primary transplantation in BA is higher compared with LT performed after PE. ${ }^{6,12,13}$ In addition, better LT outcomes are achieved in older children compared with infants, ${ }^{11,40}$ which supports the benefit of primary PE unless patients present with liver failure. As malnutrition and stage of liver disease also influence LT outcomes, ${ }^{39,40}$ management of BA in centers with experienced multidisciplinary teams and a transplantation program likely improves patient survival by ensuring appropriate management, as well as timely listing for LT when needed. ${ }^{10}$ Centralization of BA treatment in a hospital with such services might, in part, explain the improved outcomes observed in our series.

Viral, autoimmune, or toxic triggers are thought to give rise to an inflammatory reaction launching destruction of bile ducts in BA. ${ }^{1,8,41}$ Different degrees of portal inflammation were present at diagnosis in virtually all of our patients, supporting a proinflammatory cause. Interestingly, higher inflammation scores strongly predicted COJ, longer native liver survival, and slower fibrosis progression. Portal inflammation reduced only after successful PE, which might have been facilitated by postoperative adjuvant therapy use after centralization. ${ }^{19}$ At PE, most BA patients present with some degree of liver inflammation, ${ }^{16,41}$ higher levels of which have been reported in cytomegalovirus-associated BA. ${ }^{42}$ Besides differential viral cause, a predominantly inflammatory liver histopathology could reflect an earlier and more modifiable stage of BA before irreversible progression to a predominantly fibrotic stage, as suggested by gene expression profiling analyses. ${ }^{41}$ We found portal inflammation scores unrelated with age at PE or clinical patient characteristics. Although our sample is limited by its relatively small size and some missing biopsies among cohort A patients, the strong inverse association between inflammation and improved outcomes appears to be a true biologic phenomenon.

The main determinant of the course of BA and need for LT is the progression fibrosis, which pathogenesis is incompletely understood. ${ }^{22,43,44}$ In BA and other cholangiopathies, a characteristic histologic feature evolving adjacent to fibrosis is ductal reaction, which refers to hepatocytes and/or progenitor cells transdifferentiating into CK7-positive cell lineages, toward either intermediate hepatocytes or epithelial cells forming immature biliary ductules. ${ }^{17,43,45}$ Although mechanisms behind ductal reaction-driven fibrogenesis remain unclear, worsening fibrosis correlates closely with increasing ductal reaction in several acquired liver diseases. ${ }^{45,46}$ In BA, degree of biliary proliferation predicts native liver survival and reflects the degree of fibrosis at time of PE. ${ }^{15,16}$ Our results demonstrate that the extent of ductal reaction and associated periportal HCM parallel closely the degree of fibrosis not only at PE but also during the course of BA, suggesting such histopathologic features can promote progressive fibrosis, even when inflammation resolves after successful PE. Notably, in multiple regression, periportal HCM was the only predictor of follow-up fibrosis. In BA animal models, fibrogenic growth factor signaling from ductal reaction seems to activate other cell types to produce extracellular matrix.. ${ }^{47,48}$ Further characterization of such interplay ${ }^{47,49,50}$ is crucial to understanding how to prevent progressive liver injury.

\section{CONCLUSIONS}

Based on more than a decade of follow-up after national centralization of BA management, outcomes measured as COJ, native liver survival, and overall survival improved significantly. Resolution of cholestasis and reduction of high-grade portal inflammation after $\mathrm{PE}$ is associated with slower fibrosis progression and improved native liver survival. Despite COJ, liver fibrosis progressed in parallel with CK7 immunostaining of proliferating bile ductules and periportal hepatocytes during follow-up, suggesting expanding biliary fibrosis in BA is closely coupled with ductal reaction and associated HCM. To what extent 
fibrogenesis and ductal reaction are affected by the initial inflammatory reaction remains to be elucidated. While waiting for effective antifibrotic therapies, standardized multidisciplinary treatment protocols, as well as centralization of BA management, can postpone the need for LT and extend patient survival.

\section{Author Contributions}

Study conception and design: Hukkinen, Kerola, Pakarinen

Acquisition of data: Hukkinen, Kerola, Lohi, Heikkilä, Merras-Salmio, Jahnukainen, Koivusalo, Jalanko, Pakarinen

Analysis and interpretation of data: Hukkinen, Kerola, Lohi, Heikkilä, Pakarinen

Drafting of manuscript: Hukkinen, Pakarinen

Critical revision: Hukkinen, Kerola, Lohi, Heikkilä, Merras-Salmio, Jahnukainen, Koivusalo, Jalanko, Pakarinen

\section{REFERENCES}

1. Asai A, Miethke A, Bezerra JA. Pathogenesis of biliary atresia: defining biology to understand clinical phenotypes. Nat Rev Gastroenterol Hepatol 2015;12:342-352.

2. Fabris L, Brivio S, Cadamuro M, Strazzabosco M. Revisiting epithelial-to-mesenchymal transition in liver fibrosis: clues for a better understanding of the "reactive" biliary epithelial phenotype. Stem Cells Int 2016;2016:2953727.

3. de Vries W, de Langen ZJ, Groen H, et al. Biliary atresia in the Netherlands: outcome of patients diagnosed between 1987 and 2008. J Pediatr 2012;160:638-644.

4. Lampela H, Ritvanen A, Kosola S, et al. National centralization of biliary atresia care to an assigned multidisciplinary team provides high-quality outcomes. Scand J Gastroenterol 2012;47:99-107.

5. Nio M, Ohi R, Miyano T, et al. Five- and 10-year survival rates after surgery for biliary atresia: a report from the Japanese Biliary Atresia Registry. J Pediatr Surg 2003;38:997-1000.

6. Serinet MO, Broue P, Jacquemin E, et al. Management of patients with biliary atresia in France: results of a decentralized policy 1986-2002. Hepatology 2006;44:75-84.

7. Schreiber RA, Barker CC, Roberts EA, et al. Biliary atresia: the Canadian experience. J Pediatr 2007;151:659-665.

8. Hartley JL, Davenport M, Kelly DA. Biliary atresia. Lancet 2009;374[9702]:1704-1713.

9. de Vries W, Homan-Van der Veen J, Hulscher JB, et al. Twentyyear transplant-free survival rate among patients with biliary atresia. Clin Gastroenterol Hepatol 2011;9:1086-1091.

10. Sundaram SS, Mack CL, Feldman AG, Sokol RJ. Biliary atresia: indications and timing of liver transplantation and optimization of pretransplant care. Liver Transpl 2017;23:96-109.

11. Arnon R, Annunziato RA, D’Amelio G, et al. Liver transplantation for biliary atresia: is there a difference in outcome for infants? J Pediatr Gastroenterol Nutr 2016;62:220-225.

12. Neto JS, Feier FH, Bierrenbach AL, et al. Impact of Kasai portoenterostomy on liver transplantation outcomes: a retrospective cohort study of 347 children with biliary atresia. Liver Transpl 2015;21:922-927.
13. Altman RP, Lilly JR, Greenfeld J, et al. A multivariable risk factor analysis of the portoenterostomy (Kasai) procedure for biliary atresia: twenty-five years of experience from two centers. Ann Surg 1997;226:348-355.

14. Superina R, Magee JC, Brandt ML, et al. The anatomic pattern of biliary atresia identified at time of Kasai hepatoportoenterostomy and early postoperative clearance of jaundice are significant predictors of transplant-free survival. Ann Surg 2011;254:577-585.

15. Santos JL, Kieling CO, Meurer L, et al. The extent of biliary proliferation in liver biopsies from patients with biliary atresia at portoenterostomy is associated with the postoperative prognosis. J Pediatr Surg 2009;44:695-701.

16. Russo P, Magee JC, Anders RA, et al. Key histopathologic features of liver biopsies that distinguish biliary atresia from other causes of infantile cholestasis and their correlation with outcome: a multicenter study. Am J Surg Pathol 2016;40:1601-1615.

17. Roskams TA, Theise ND, Balabaud C, et al. Nomenclature of the finer branches of the biliary tree: canals, ductules, and ductular reactions in human livers. Hepatology 2004;39:1739-1745.

18. Weerasooriya VS, White FV, Shepherd RW. Hepatic fibrosis and survival in biliary atresia. J Pediatr 2004;144:123-125.

19. Davenport M, Parsons C, Tizzard S, Hadzic N. Steroids in biliary atresia: single surgeon, single centre, prospective study. J Hepatol 2013;59:1054-1058.

20. Bezerra JA, Spino C, Magee JC, et al. Use of corticosteroids after hepatoportoenterostomy for bile drainage in infants with biliary atresia: the START randomized clinical trial. JAMA 2014;311:1750-1759.

21. Davenport M, Ong E, Sharif K, et al. Biliary atresia in England and Wales: results of centralization and new benchmark. J Pediatr Surg 2011;46:1689-1694.

22. Lampela H, Kosola S, Heikkila P, et al. Native liver histology after successful portoenterostomy in biliary atresia. J Clin Gastroenterol 2014;48:721-728.

23. Ohi R, Ibrahim M. Biliary atresia. Semin Pediatr Surg 1992;1: $115-124$.

24. Davenport M, Tizzard SA, Underhill J, et al. The biliary atresia splenic malformation syndrome: a 28-year singlecenter retrospective study. J Pediatr 2006;149:393-400.

25. Davenport M, Stringer MD, Tizzard SA, et al. Randomized, doubleblind, placebo-controlled trial of corticosteroids after Kasai portoenterostomy for biliary atresia. Hepatology 2007;46:1821-1827.

26. Decharun K, Leys CM, West KW, Finnell SME. Prophylactic antibiotics for prevention of cholangitis in patients with biliary atresia status post-Kasai portoenterostomy: a systematic review. Clin Pediatr (Phila) 2016;55:66-72.

27. Willot S, Uhlen S, Michaud L, et al. Effect of ursodeoxycholic acid on liver function in children after successful surgery for biliary atresia. Pediatrics 2008;122:e1236-e1241.

28. Baker A, Stevenson R, Dhawan A, et al. Guidelines for nutritional care for infants with cholestatic liver disease before liver transplantation. Pediatr Transplant 2007;11[8]:825-834.

29. Lampela H, Kosola S, Koivusalo A, et al. Endoscopic surveillance and primary prophylaxis sclerotherapy of esophageal varices in biliary atresia. J Pediatr Gastroenterol Nutr 2012;55:574-579.

30. Bedossa P, Poynard T. An algorithm for the grading of activity in chronic hepatitis C. The METAVIR cooperative study group. Hepatology 1996;24:289-293.

31. Official Statistics of Finland. Births. ISSN $=1798-2391$. Helsinki: Statistics Finland; 2017. Available at: http://www. stat.fi/til/synt/index.html. Accessed September 27, 2017. 
32. Shneider BL, Brown MB, Haber B, et al. A multicenter study of the outcome of biliary atresia in the United States, 1997 to 2000. J Pediatr 2006; 148:467-474.

33. Chardot C, Buet C, Serinet MO, et al. Improving outcomes of biliary atresia: French national series 1986-2009. J Hepatol 2013;58:1209-1217.

34. Schreiber RA, Barker CC, Roberts EA, et al. Biliary atresia in Canada: the effect of centre caseload experience on outcome. J Pediatr Gastroenterol Nutr 2010;51:61-65.

35. Meyers RL, Book LS, O'Gorman MA, et al. High-dose steroids, ursodeoxycholic acid, and chronic intravenous antibiotics improve bile flow after Kasai procedure in infants with biliary atresia. J Pediatr Surg 2003;38:406-411.

36. Stringer MD, Davison SM, Rajwal SR, McClean P. Kasai portoenterostomy: 12-year experience with a novel adjuvant therapy regimen. J Pediatr Surg 2007;42:1324-1328.

37. Shneider BL, Magee JC, Karpen SJ, et al. Total serum bilirubin within 3 months of hepatoportoenterostomy predicts short-term outcomes in biliary atresia. J Pediatr 2016;170: 211-217.e1-e2.

38. Nightingale S, Stormon MO, O'Loughlin EV, et al. Early posthepatoportoenterostomy predictors of native liver survival in biliary atresia. J Pediatr Gastroenterol Nutr 2017;64:203-209.

39. DeRusso PA, Ye W, Shepherd R, et al. Growth failure and outcomes in infants with biliary atresia: a report from the biliary atresia research consortium. Hepatology 2007;46: 1632-1638.

40. Malenicka S, Ericzon BG, Jorgensen $\mathrm{MH}$, et al. Impaired intention-to-treat survival after listing for liver transplantation in children with biliary atresia compared to other chronic liver diseases: 20 years' experience from the Nordic countries. Pediatr Transplant 2017;21:e12851.
41. Moyer K, Kaimal V, Pacheco C, et al. Staging of biliary atresia at diagnosis by molecular profiling of the liver. Genome Med 2010;2:33.

42. Zani A, Quaglia A, Hadzic N, et al. Cytomegalovirus-associated biliary atresia: an aetiological and prognostic subgroup. J Pediatr Surg 2015;50:1739-1745.

43. Kuo FY, Huang CC, Chen CL, et al. Immunohistochemical characterization of the regenerative compartment in biliary atresia: a comparison between Kasai procedure and transplant cases. Hum Pathol 2015;46:1633-1639.

44. Tomita H, Masugi $Y$, Hoshino K, et al. Long-term native liver fibrosis in biliary atresia: development of a novel scoring system using histology and standard liver tests. J Hepatol 2014; 60:1242-1248.

45. Gouw AS, Clouston AD, Theise ND. Ductular reactions in human liver: diversity at the interface. Hepatology 2011;54: 1853-1863.

46. Williams MJ, Clouston AD, Forbes SJ. Links between hepatic fibrosis, ductular reaction, and progenitor cell expansion. Gastroenterology 2014;146:349-356.

47. Mavila N, James D, Shivakumar P, et al. Expansion of prominin-1-expressing cells in association with fibrosis of biliary atresia. Hepatology 2014;60:941-953.

48. Nguyen MV, Zagory JA, Dietz WH, et al. Hepatic prominin1 expression is associated with biliary fibrosis. Surgery 2017; 161:1266-1272.

49. Glaser SS, Gaudio E, Miller T, et al. Cholangiocyte proliferation and liver fibrosis. Expert Rev Mol Med 2009;11:e7.

50. Kerola A, Lampela H, Lohi J, et al. Increased MMP-7 expression in biliary epithelium and serum underpins native liver fibrosis after successful portoenterostomy in biliary atresia. J Pathol Clin Res 2016;2:187-198. 
eTable 1. Baseline Characteristics and Liver Biopsy Findings at Portoenterostomy in Relation to Clearance of Jaundice Characteristic

No COJ after PE $(\mathbf{n}=\mathbf{2 1})$

$\operatorname{CoJ}(\mathbf{n}=\mathbf{3 8})$

p Value

Gestational age, wk, median (IQR)

$40(38-41)$

$39(38-40)$

0.575

Gestational weight, g, median (IQR)

$3,630(3,315-3,825)$

$3,250(3,003-3,640)$

0.020

Type of biliary atresia, $\mathrm{n}(\%)$

\begin{tabular}{|c|c|c|c|}
\hline 1 & $1(4.7)$ & $1(2.6)$ & 1.000 \\
\hline 2 & $1(4.7)$ & $3(7.9)$ & \\
\hline 3 & $19(90)$ & $34(89)$ & \\
\hline Age at PE, d, median (IQR) & $75(54-100)$ & $56(29-78)$ & 0.013 \\
\hline Associated malformations, $\mathrm{n}(\%)$ & $6(29)$ & $15(39)$ & 0.571 \\
\hline Biliary atresia splenic malformation, n (\%) & $3(14)$ & $7(18)$ & 1.000 \\
\hline Preoperative bilirubin, $\mu \mathrm{mol} / \mathrm{L}$, median (IQR) & $176(142-195)$ & $159(110-213)$ & 0.322 \\
\hline \multicolumn{4}{|l|}{ Liver histology at PE, mean (range) } \\
\hline Fibrosis, Metavir, $0-4$ & $2.54(3)$ & $2.45(3)$ & 0.925 \\
\hline Portal inflammation, $0-3$ & $1.46(3)$ & $2.18(2)$ & 0.008 \\
\hline \multicolumn{4}{|l|}{ Cholestasis, mean (range) } \\
\hline Intracellular, $0-3$ & $1.92(2)$ & $2.09(2)$ & 0.533 \\
\hline Intracanalicular, $0-3$ & $2.15(2)$ & $2.33(2)$ & 0.290 \\
\hline Ductal, $0-3$ & $1.67(3)$ & $1.33(3)$ & 0.409 \\
\hline \multicolumn{4}{|l|}{ Cytokeratin 7 immunostaining, mean (range) } \\
\hline Periportal hepatocytes, $0-4$ & $1.33(2)$ & $1.16(2)$ & 0.427 \\
\hline Proliferating bile ductules, $0-2$ & $1.67(1)$ & $1.31(2)$ & 0.177 \\
\hline
\end{tabular}

COJ, clearance of jaundice; IQR, interquartile range; PE, portoenterostomy. 